\title{
College English Teaching Quality Monitoring and Intelligent Analysis Based on Internet of Things Technology
}

\author{
Xin Wang \\ Foreign Language Department, Xuzhou Medical University, Jiangsu 221000, China \\ Correspondence should be addressed to Xin Wang; 100000103024@xzhmu.edu.cn
}

Received 4 January 2022; Revised 29 January 2022; Accepted 14 February 2022; Published 5 March 2022

Academic Editor: Zhiguo Qu

Copyright () 2022 Xin Wang. This is an open access article distributed under the Creative Commons Attribution License, which permits unrestricted use, distribution, and reproduction in any medium, provided the original work is properly cited.

\begin{abstract}
With the continuous development of network communication, modern control, information perception, artificial intelligence, and other technologies, the Internet of Things technology has also been more comprehensively developed and grown, and it is playing an increasingly important role in various fields of production and life. Due to the low efficiency and cumbersome procedures of the existing college English teaching quality assessment, this study intends to propose a new method to deal with this problem. Through this research, we get the following: (1) use static weight equalization method, dynamic weight adaptation method, and iterative weight method to filter and analyze the original data received by mobile phones and discard some obviously wrong values in the preprocessing. Analyzing the number requirements of the game model, the supply operation reference model, and the IoT technology upgrade model for the number of demand points, the results show that the IoT technology upgrade model requires the least number of demand points. (2) Optimize the related parameter information of the IoT system model, including candidate numbers, number of students in class, adjustment coefficient, Di, turnover rate, system cost, and total system consumption. The Internet of Things technology upgrade model performed best. Adjustment coefficient $=-102$; $\mathrm{Di}=-99.6$; turnover $=-100$; system cost $=-123.2$; $\mathrm{SL}=-123.5$; $\mathrm{SP}=-99.8$. (3) Passed the test of the number of questions and feedback rate, classroom number, classroom test scores, new vocabulary number, system scoring, and comprehensive scoring to judge the model. It is found that the number of questions, feedback rate, class number, and class test scores, number of new vocabularies, system scores, and comprehensive scores of the upgraded and transformed models of the Internet of Things are above the standard values, indicating that the model is highly efficient and intelligent.
\end{abstract}

\section{Introduction}

The concept of Internet of Things (IoT) is that when scientists are studying the interaction based on the Internet, they discovered that Internet technology can be perfectly combined with radio signal transmission technology, so the Internet of Things technology is proposed. Its purpose is to realize the interconnection of all things, build an intelligent metropolis, and improve the standard and quality of human life, and then, realize the intelligent recognition and management [1-3]. With the continuous development of network communication, modern control, information perception, artificial intelligence, and other technologies, the Internet of Things technology has also been more comprehensively developed and grown, and it is playing an increasing role in various fields of production and life. COVID-19 has transcended, radical, conceptual, spiritual, social, and teaching boundaries for global challenges. Great changes have taken place in our lives, and medical diagnosis based on the Internet of Things has also emerged. This detection method greatly improves the efficiency of data integration of testers and shortens the detection time of the new coronavirus. The tide of the fourth industrial revolution has swept the world [4]. The Internet of Things technology covers many fields such as manufacturing, agriculture, health, monitoring, and education [5-7]. In order to increase the sense of experience of the Internet of Things, enhance the sense of participation, and increase comfort, technological innovations, increased sensor distribution, design of more userfriendly interactive interfaces, and adaptation of more applications can be achieved. The solutions to the problems in life through the Internet of Things technology are applied in 


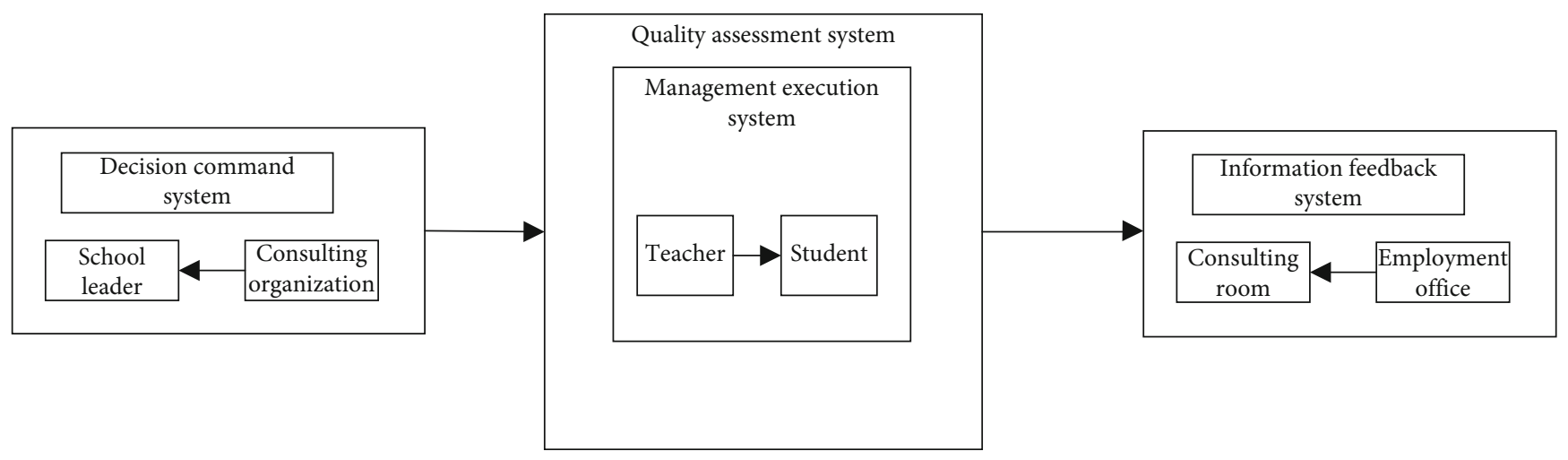

FIGURE 1: Teaching quality evaluation system.

TABLE 1: Course arrangement of simulated English teaching.

\begin{tabular}{lcc}
\hline Week & Units & Functions \\
\hline 1 & Unit 1. Where did you go on vacation? & Talk about past events \\
2 & Unit 2. How often do you exercise? & Talk about how often you do things \\
3 and 4 & Unit 3. I am more outgoing than my sister. & Talk about personal traits; Compare people \\
5 and 6 & Unit 4. What is the best movie theater? & Discuss preferences; make comparisons \\
7 and 8 & Unit 5. Do you want to watch a game show? & Talk about preferences make plans \\
9 and 10 & Unit 6 . I am going to study computer science. & Talk about future; intentions \\
11 and 12 & Unit 7. Will people have robots? & Make predictions \\
13 and 14 & Unit 8 . How do you make a banana milk shake? & Describe a process follow instructions \\
15 and 16 & Unit 9. Can you come to my party? & Talke, accept and decline invitations; talk about obligations \\
17 and 18 & Unit 10. If you go to the party, you will have a great time! &
\end{tabular}

more and more fields, and the application in each field has its specificity, bringing huge challenges to the deployment of the Internet of Things [8-10]. As the global population continues to age, the health supervision needs of the elderly are increasing. The Internet of Things technology is being used to detect the daily life and dietary health of the elderly. In this way, even if the elderly live alone, there is no need to worry too much. What needs to be solved is the privacy problem involved in the monitoring process. How to better protect privacy is the main problem we are facing now. The use of the Internet of Things technology to enhance the protection of privacy and security and the setting of the whitelist will bring great convenience to the healthy life of human beings. Through the open data set, a smart space that is versatile, open, and inclusive is constructed. In the current trend of intelligent digitization, the Internet of Things needs to use data sensing technology for dimensionality reduction processing of high-dimensional data sets, relying on the powerful network environment and the selflearning function of the deep system. Dynamic image classification is associated with several temporal data disturbances (such as new class arrival and class evolution problems), which can cause serious deterioration of the classification in the deployed classification model and make it invalid. The teaching evaluation system consists of three modules, namely, the decision-making command system, the quality evaluation system, and the information feedback system.
The decision-making command system is composed of school leaders including school leaders and consulting organizations. School-level leaders are responsible for the formulation and modification of some policies, while the consulting organization conducts anonymous questionnaire surveys on some of the needs of students and analyzes the results of the survey. Find out the most concerned issues of the students and agree to solve them. After reporting to school-level leaders, make decisions. The teaching quality evaluation and monitoring system includes strengthening the expansion of the campus monitoring network coverage, the continuous update and improvement of the teaching information system, and the optimization and purification of the network environment for students to surf the Internet. The monitoring of teaching quality also includes the combination of practical teaching and theoretical teaching [11-13]. After comparing practical teaching and theoretical teaching, it is found that each has its own advantages and disadvantages. Practical teaching relies more on experience, while theoretical teaching focuses more on the understanding of knowledge and the derivation of logic. In order to improve the English classroom learning effect of the university, facilitate the management and statistics of teachers, analyze the classroom behavior of college students on the Internet of Things technology, and identify when the students are most focused and when they feel the classroom boring and boring, and then use the deep learning model 
TABLE 2: The structure of strengthening multimodal reading teaching.

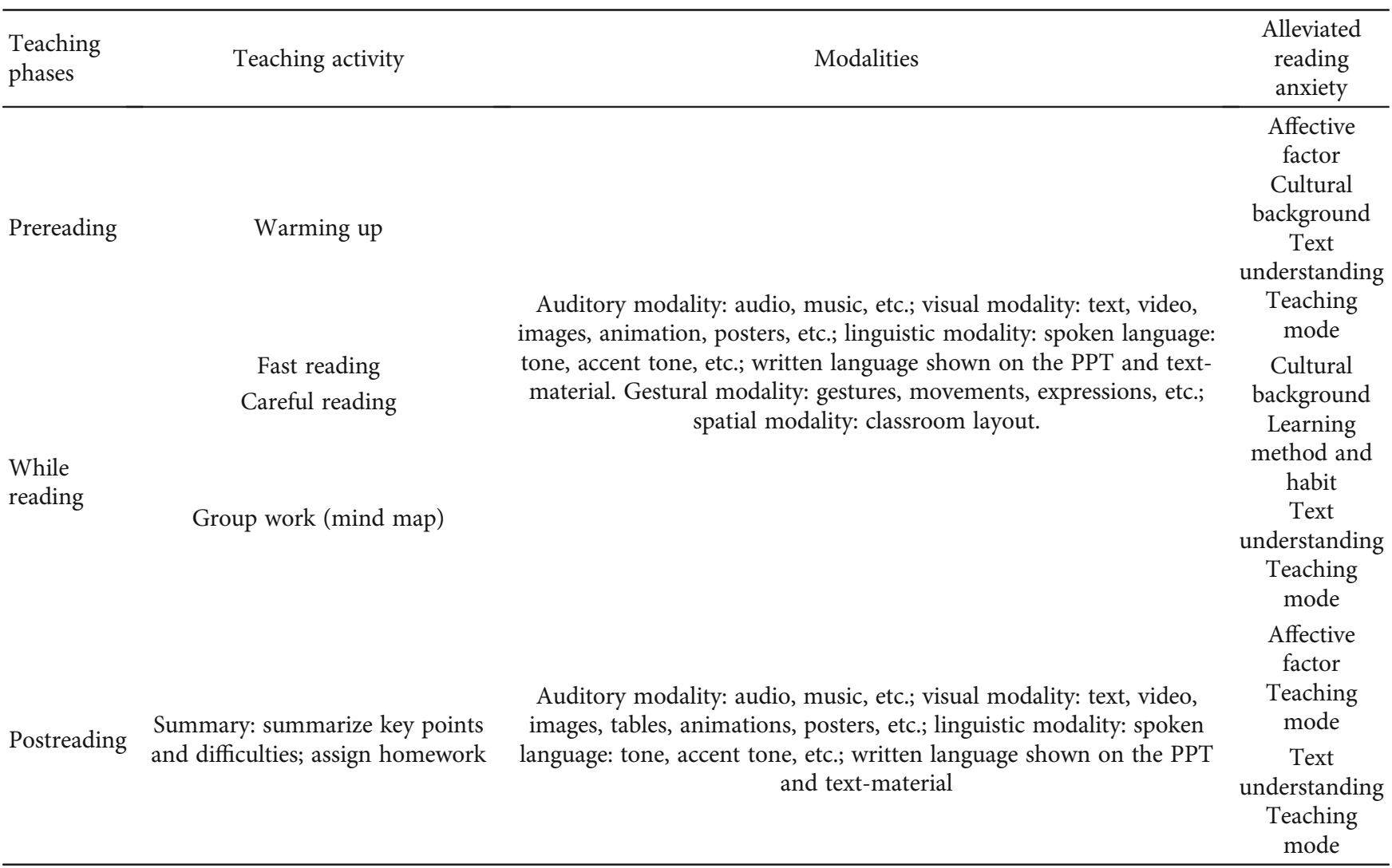

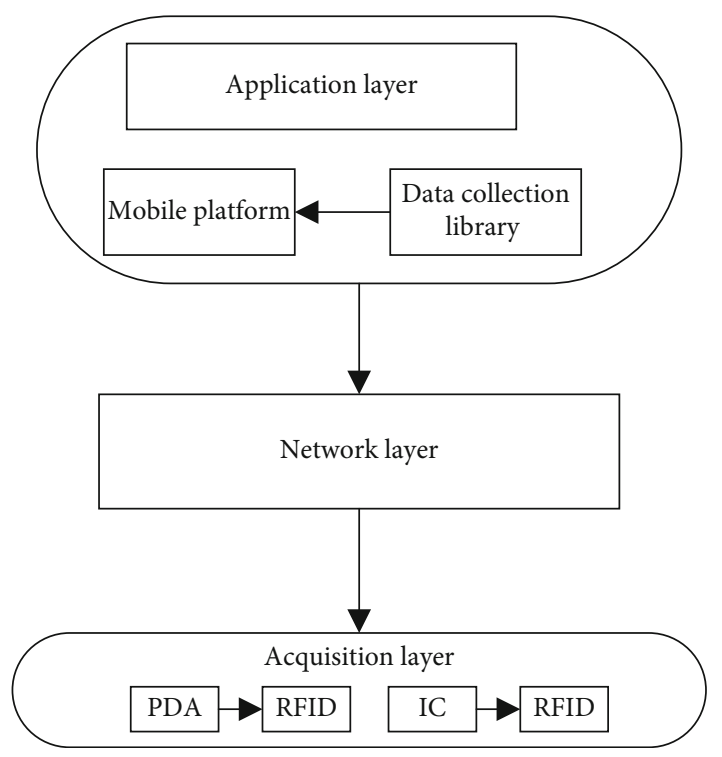

Figure 2: The overall design of the system.

to analyze the captured images. Analyze the source of influence, so as to better improve. College English teaching quality monitoring and intelligent analysis include parameters such as candidate numbers, class numbers, and adjustment coefficients. Adjusting these key parameters can make the functions of the college English teaching quality monitoring and intelligent analysis system more perfect. In order to obtain and master some of the needs of students, find out the most concerned problems of students and solve them in a unified way. Pass the verification report of four models (VGG16 model, ResNet18 model, ResNet50 model, and AlexNet model). It is concluded that the algorithm recognition ability of the VGG16 model is the strongest, and the accuracy rate for the recognition of students' classroom behavior is as high as $90 \%$. Intelligent image recognition technology based on the Internet of Things technology can improve the efficiency of college English classrooms. This idea is feasible. Due to the low efficiency and cumbersome procedures of the existing college English teaching quality assessment, this study intends to propose a new method to deal with this problem. This research is based on the Internet of Things technology, through online training (OT) and online classifier update (OCU) modules, using a new framework architecture model, and is verified in the quality monitoring and intelligent analysis of college students' English teaching, which effectively proves the adaptation, the advanced nature of the framework algorithm and architecture. Using adaptive algorithms, an adaptive college English teaching quality monitoring and intelligent analysis system supporting the Internet of Things has been developed. Solve the problem of inconsistency between new class arrival and class evolution $[14,15]$. 
TABLe 3: Raw data cleaning and filtering scheme.

\begin{tabular}{lcccccccccc}
\hline Method & 1 & 2 & 3 & 4 & 5 & 6 & 7 & 8 \\
\hline Static weight equalization method. & 0.150 & 0.145 & 0.135 & 0.105 & 0.094 & 0.085 & 0.097 & 0.147 & 0.152 \\
Dynamic weight adaptation & 0.073 & 0.078 & 0.065 & 0.072 & 0.058 & 0.059 & 0.074 & 0.072 & 0.066 \\
Iterative weight method & 0.065 & 0.059 & 0.048 & 0.049 & 0.052 & 0.042 & 0.047 & 0.053 & 0.056 \\
\hline
\end{tabular}

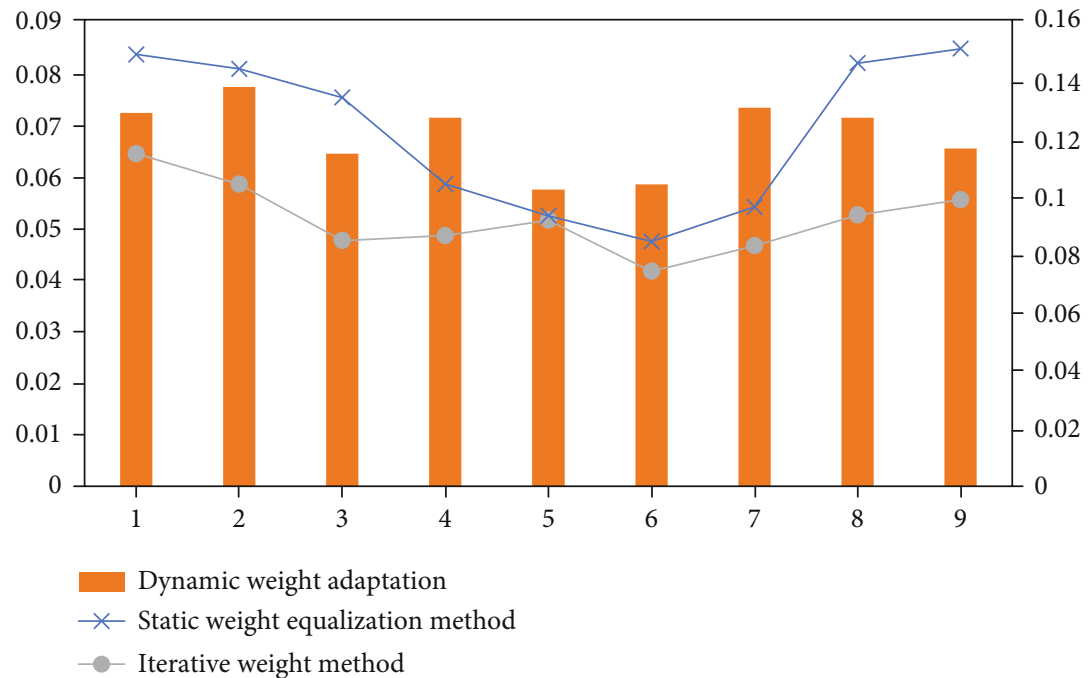

Figure 3: Original data cleaning and filtering scheme.

TABLe 4: Game model, supply chain operation reference model, and IoT technology upgrade model demand points.

\begin{tabular}{lcccccccccc}
\hline Model & $\begin{array}{c}\text { Demand } \\
\text { point 301 }\end{array}$ & $\begin{array}{c}\text { Demand } \\
\text { point 302 }\end{array}$ & $\begin{array}{c}\text { Demand } \\
\text { point 303 }\end{array}$ & $\begin{array}{c}\text { Demand } \\
\text { point 304 }\end{array}$ & $\begin{array}{c}\text { Demand } \\
\text { point 305 }\end{array}$ & $\begin{array}{c}\text { Demand } \\
\text { point 306 }\end{array}$ & $\begin{array}{c}\text { Demand } \\
\text { point 307 }\end{array}$ & $\begin{array}{c}\text { Demand } \\
\text { point 308 }\end{array}$ & $\begin{array}{c}\text { Demand } \\
\text { point 309 }\end{array}$ & $\begin{array}{c}\text { Demand } \\
\text { point 310 }\end{array}$ \\
\hline $\begin{array}{l}\text { Game model } \\
\begin{array}{l}\text { Supply chain } \\
\text { operation reference } \\
\text { model }\end{array}\end{array}$ & 8.9 & 21.9 & 27 & 16 & 21 & 10 & 12.4 & 24 & 12.5 & 13.2 \\
\begin{tabular}{l} 
Internet of Things \\
\hline
\end{tabular} & 8.2 & 10.8 & 8.6 & 9.3 & 22 & 13.2 & 5.6 & 2.2 & 7.6 & 5.4 \\
\end{tabular}

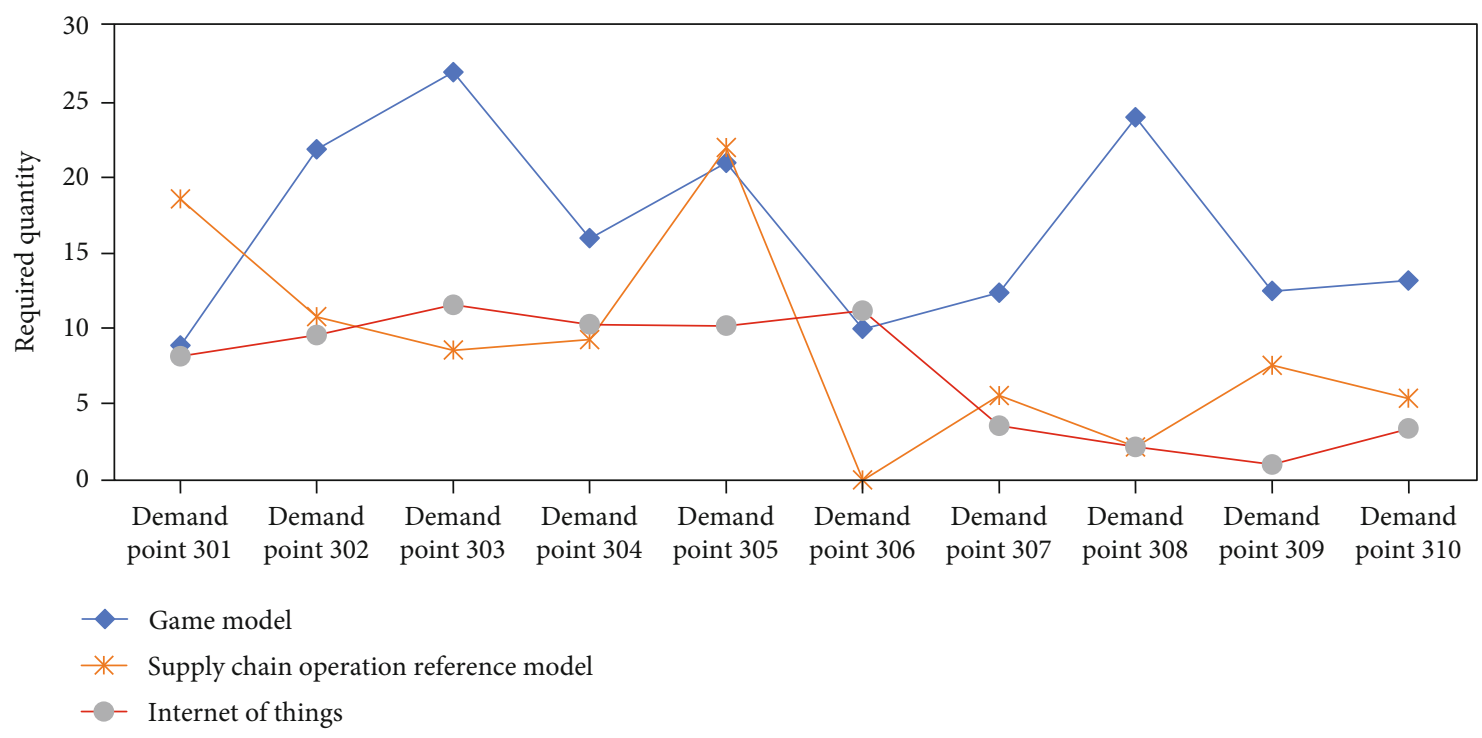

FIGURE 4: Game model, supply chain operation reference model, and IoT technology upgrade model demand points. 
TABLE 5: Related parameters.

\begin{tabular}{lcccccc}
\hline Alternative number & Number of class & Adjustment coefficient & Di & Turnover & System cost & Total system consumption \\
\hline 201 & 152 & 1.14 & 70 & 122 & 0.92 & 3.19 \\
202 & 165 & 1.13 & 50 & 122 & 0.92 & 3.19 \\
203 & 154 & 1.15 & 70 & 122 & 0.92 & 3.19 \\
204 & 198 & 1.18 & 70 & 122 & 0.92 & 3.19 \\
205 & 156 & 1.19 & 50 & 122 & 0.92 & 3.19 \\
\hline
\end{tabular}

TABLE 6: Value range of spreading factor.

\begin{tabular}{lcc}
\hline $\begin{array}{l}\text { Spreading } \\
\text { factor }\end{array}$ & $\begin{array}{c}\text { Spreading factor } \\
\text { (chips/symbol) }\end{array}$ & $\begin{array}{c}\text { The signal-to-noise ratio } \\
\text { SNR of the signal. }\end{array}$ \\
\hline 7 & 128 & $-7.5 \mathrm{~dB}$ \\
8 & 256 & $-10 \mathrm{~dB}$ \\
9 & 512 & $-12.5 \mathrm{~dB}$ \\
10 & 1024 & $-15 \mathrm{~dB}$ \\
11 & 2084 & $-17.5 \mathrm{~dB}$ \\
12 & 4096 & $-20 \mathrm{~dB}$ \\
\hline
\end{tabular}

\section{Teaching Quality Monitoring and Intelligent Analysis}

2.1. Teaching Quality Evaluation System. As shown in Figure 1, the teaching evaluation system consists of three modules, namely, the decision-making command system, the quality evaluation system, and the information feedback system. The decision-making command system is composed of school leaders including school leaders and consulting organizations. School-level leaders are responsible for the formulation and modification of some policies, while the consulting organization conducts anonymous questionnaire surveys on some of the needs of students and analyzes the results of the survey. Find out the most concerned issues of the students and agree to solve them. After reporting to school-level leaders, make decisions. The management execution system also includes the school-level administrative department's implementation and interpretation of higherlevel policies and interpretation of the latest guiding ideology of the Academic Affairs Office. Teachers and students play the role of data sources. The information feedback system is composed of the roommate supervision office and the employment office, responsible for the supervision and promotion of the implementation of the project, such as the classroom attendance of college students, and the employment of graduates. The feedback link in the information feedback system mainly accepts feedback from evaluation subjects such as the supervision office and educational administration and society, and the four links of teaching quality monitoring are interrelated and permeate each other [16-19].

2.2. Course Arrangement of Simulated English Teaching. According to a semester of 18 weeks, the English courses are arranged to make the teaching more planned and organized, as shown in Table 1 . The weekly course schedule and classroom interaction are listed separately [20].
2.3. Strengthen the Structure of Multimodal Reading Teaching. Selection principle is based on modal system, as well as the current English reading teaching procedures (prereading, midreading, and postreading); the English reading teaching steps are divided into three stages. To carry out intensive multimodal reading teaching, follow the steps below to output, as shown in Table 2 .

2.4. Overall System Design. The application layer calls and analyzes the college English classroom data through the college English database for the entry and exit management application and finally displays the data of teaching quality monitoring and intelligent management through visualization technology; the network layer is mainly responsible for the communication between the application layer and the collection layer; this technical service can evaluate teaching quality monitoring and intelligent management; the collection layer is mainly responsible for the attribute data information of college English teaching quality in Figure 2.

\section{The Application of Internet of Things Technology in College English Teaching Quality Monitoring and Intelligent Analysis}

(a) Game model [21]:

$$
\frac{1}{x_{k}} \frac{d x_{k}}{d t}=[u(k, s)-u(s, s)], \quad k=1
$$

Adaptability of college English class:

$$
\begin{gathered}
u_{s}\left(C_{\infty}, J\right)=y\left(x_{s}+\Delta V_{s}\right)+(1-y)\left(x_{s}-C_{O S}\right), \\
u_{s}=\left(C_{O M}, J\right)=y \times \pi_{s}+(1-y) \pi_{s} .
\end{gathered}
$$

Average node fitness:

$$
\bar{u}_{s}=x u_{s}\left(C_{O O}, J\right)+(1-x) u_{s}\left(C_{O M}, J\right) .
$$

Student cooperation strategy:

$$
\begin{gathered}
\frac{d x}{d t}=x\left[u_{s}\left(C_{O O}, J\right)-\bar{u}_{s}\right] \\
\left.\frac{d x}{d t}=x(1-x)\left[\Delta V_{s} u+C_{O S}\right) y-C_{O S}\right] .
\end{gathered}
$$




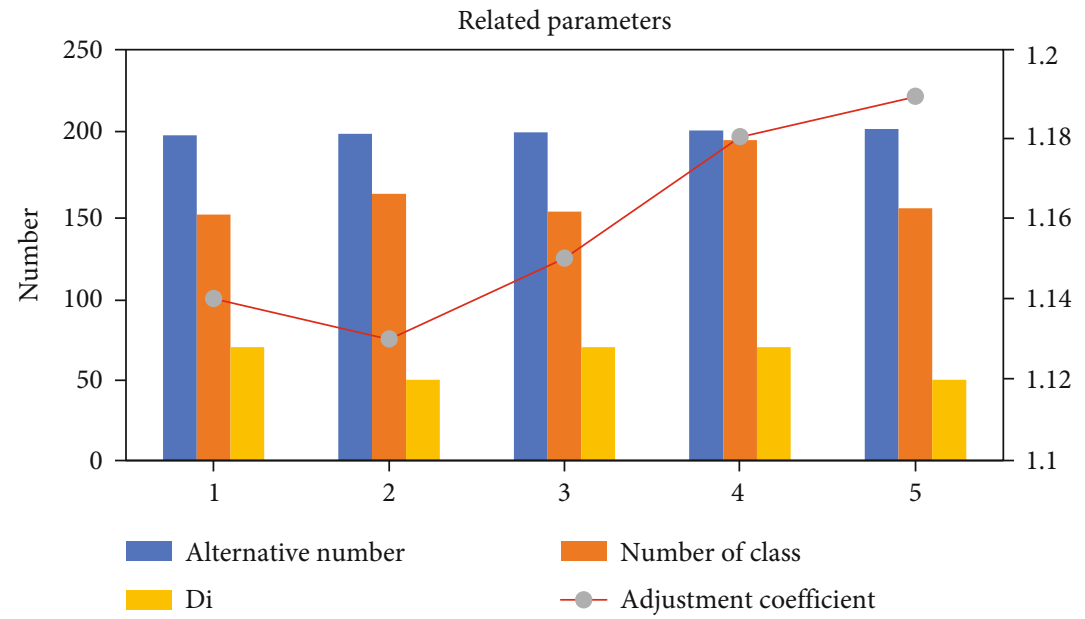

FIGURE 5: Teaching quality monitoring parameters.

TABLE 7: Sensitivity test of different models.

\begin{tabular}{lccc}
\hline Test & $\begin{array}{c}\text { Game } \\
\text { model }\end{array}$ & $\begin{array}{c}\text { Supply chain operation } \\
\text { reference model }\end{array}$ & $\begin{array}{c}\text { Internet of } \\
\text { Things }\end{array}$ \\
\hline $\begin{array}{l}\text { Adjustment } \\
\text { coefficient }\end{array}$ & -130.00 & -127.00 & -102.00 \\
Di & -132.50 & -129.50 & -99.60 \\
Turnover & -135.00 & -132.00 & -100.00 \\
System cost & -137.50 & -134.50 & -123.20 \\
SL & -140.00 & -137.00 & -123.50 \\
SP & -142.50 & -139.50 & -99.80 \\
\hline
\end{tabular}

Define game strategy:

$$
N=\left\{n_{1}, n_{2}, n_{3}\right\},
$$

$P(N)=\left\{\left\{n_{0}\right\},\left\{n_{1}\right\},\left\{n_{2}\right\},\left\{n_{3}\right\},\left\{n_{1}, n_{2}\right\},\left\{n_{1}, n_{3}\right\},\left\{n_{2}, n_{3}\right\},\left\{n_{1}, n_{2}, n_{3}\right\}, N\right\}$.

(b) Supply operation reference model (SCOR) [22]: classes:

Competitive strategies of adaptability in college English

$$
v\left(\left\{n_{0}\right\}\right)=0, v(N)=2 \theta .
$$

For capturing images of college students:

$$
\begin{gathered}
v\left(\left\{n_{1}\right\}\right)=v\left(\left\{n_{2}\right\}\right)=v\left(\left\{n_{3}\right\}\right)=0, \\
v\left(\left\{n_{1}, n_{j}\right\}\right)=\theta,(j=2,3), \\
v\left(\left\{n_{2}, n_{3}\right\}\right)=0, \\
v\left(\left\{n_{1}, n_{2}, n_{3}\right\}\right)=2 \theta .
\end{gathered}
$$

Analyze the classroom behavior of college students on the Internet of Things technology and identify when students are most focused and when they find the class to be boring and boring.

$$
\begin{gathered}
m\left(\left\{n_{1}\right\}\right)=v\left(\left\{n_{1}\right\}\right)-v\left(\left\{n_{0}\right\}\right)=0, \\
m\left(\left\{n_{1}, n_{2}\right\}\right)=v\left(\left\{n_{1}, n_{2}\right\}\right)-v\left(\left\{n_{1}\right\}\right)=\theta, \\
m\left(\left\{n_{1}, n_{3}\right\}\right)=v\left(\left\{n_{1}, n_{3}\right\}\right)-v\left(\left\{n_{1}\right\}\right)=\theta, \\
m_{1}\left(\left\{n_{1}, n_{2}, n_{3}\right\}\right)=v\left(\left\{n_{1}, n_{2}, n_{3}\right\}\right)-v\left(\left\{n_{2}, n_{3}\right\}\right)=2 \theta .
\end{gathered}
$$

Expected contribution margin:

$$
\varphi(N, v)=\sum_{\tau \in N} \frac{(|\tau-1| !(N-|\tau|) !)}{N !} M_{i}
$$

The differential evolution process of the technological transformation and upgrading of the Internet of Things is

$$
\begin{aligned}
& \frac{d I_{H}(t)}{d t}=\beta_{m}^{H} N(t)-\alpha_{H} M_{H}(t), \\
& \frac{d I_{D}(t)}{d t}=\beta_{m}^{D} N(t)-\alpha_{D} M_{D}(t) .
\end{aligned}
$$

Internet of things technology upgrade model [23-27]:

$$
\begin{aligned}
& X_{H}(t)=\frac{\gamma_{H}}{2} M_{H}(t)^{2}, \\
& X_{D}(t)=\frac{\gamma_{D}}{2} M_{D}(t)^{2} .
\end{aligned}
$$

For the capture of classroom images of college students:

$$
\begin{gathered}
N(t)=N_{0}+\theta\left(I_{0}-I_{H}(t)\right), \\
I_{0}=\left(\beta_{m}^{D}+\beta_{m}^{H}\right) N_{0} .
\end{gathered}
$$

The cost of upgrading and reforming the Internet of 


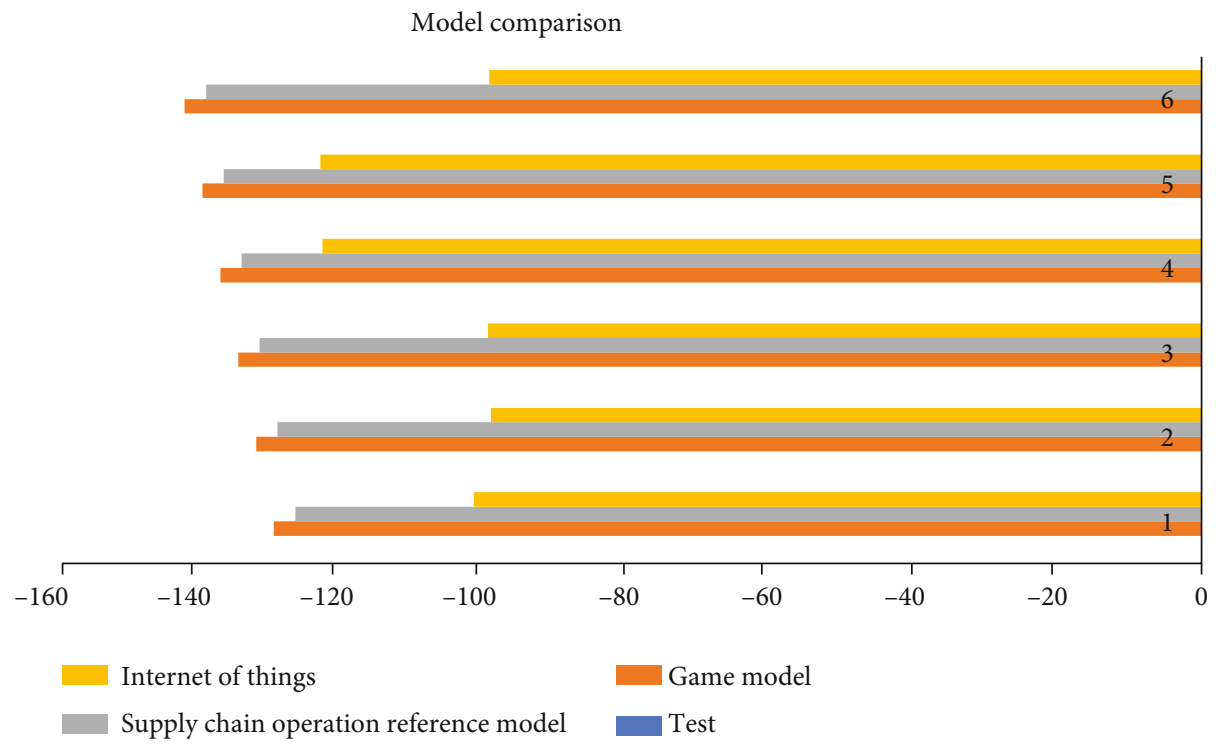

FIGURE 6: Sensitivity test of different models.

TABLE 8: The actual measurement of the IoT technology optimization model in the English classroom.

\begin{tabular}{lccccccccc}
\hline Measurement parameters & 1 & 2 & 3 & 4 & 5 & 6 & 8 & 9 \\
\hline Questions & 18.1 & 18.5 & 19 & 19.4 & 20.2 & 20.8 & 21.4 & 21.9 & 22.5 \\
Feedback rate & 85.2 & 84.8 & 84 & 82.5 & 82.1 & 81.4 & 80.9 & 80.6 & 80.1 \\
Number of class & 22 & 23 & 23 & 24 & 24 & 25 & 26 & 27 & 28 \\
Class test results & 85.1 & 84.4 & 83.6 & 82.2 & 814 & 81.1 & 80.5 & 80.2 & 79.5 \\
Number of new words & 39.1 & 39.5 & 40.2 & 40.4 & 41.2 & 41.9 & 42.2 & 42.5 & 42.9 \\
System scoring & 420 & 415 & 411 & 408 & 405 & 403 & 400 & 395 & 392 \\
Comprehensive scoring & 925 & 930 & 932 & 950 & 966 & 980 & 992 & 1005 & 1010 \\
\hline
\end{tabular}

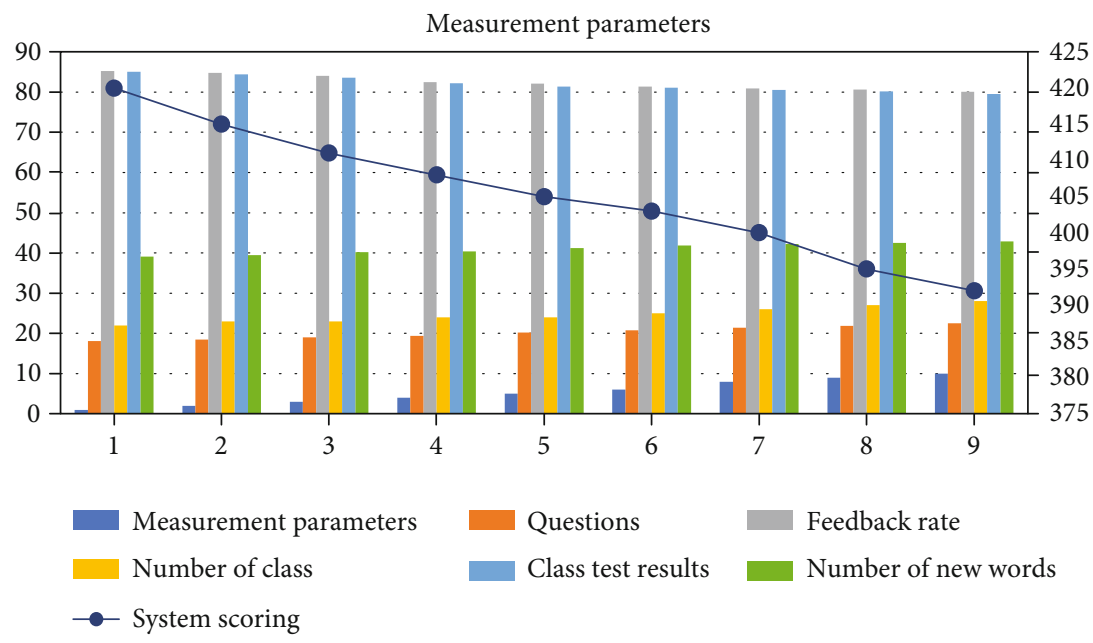

Figure 7: The actual measurement of the IoT technology optimization model in the English classroom. 
Things technology is related to efficiency:

$$
\begin{aligned}
& X_{H}(t)=P\left(I_{H}(t)-\tilde{I}_{H}\right), \\
& X_{D}(t)=P\left(I_{D}(t)-\tilde{I}_{D}\right) .
\end{aligned}
$$

Optimal efficiency of investment in IoT technology upgrading:

$$
\begin{gathered}
Y_{m}\left(I_{D}, I_{H}\right)=\varphi_{m}+\phi_{m D}{ }^{*}+\phi_{m H}{ }^{*} I_{H}, \\
Y_{n}\left(I_{D}, I_{H}\right)=\varphi_{n}+\phi_{n D}{ }^{*}+\phi_{n H}\left(I_{D}+I_{H}\right) .
\end{gathered}
$$

Evaluation results of the upgrading and transformation of the Internet of Things technology:

$$
f(D(t), H(t))=\int_{0}^{\infty}\left(I_{H} N_{H}(t)+I_{D} N_{D}(t)-\frac{\gamma_{H}}{2} H(t)^{2}\right) d t .
$$

\section{Simulation Experiment}

4.1. Calculation Example and Analysis. The static weight equalization method, dynamic weight adaptation method, and iterative weight method are used to filter and analyze the original data from the mobile phone, and some values with obvious errors are discarded in the preprocessing, as shown in Table 3 and Figure 3. Analyze the number of demand points required by the game model, the supply chain operation reference model, and the IoT technology upgrade model, as shown in Table 4 and Figure 4.

4.2. Related Parameters. As shown in Table 5, the relevant parameter information of the IoT system model is listed, including candidate numbers, number of students in class, adjustment coefficient, Di, turnover rate, system cost, and total system consumption. The alternative number refers to the number of the English classroom. According to school's arrangement of the courses, find the free classroom for systematic simulation. Table 6 lists the range of spreading factor values.

4.3. Teaching Quality Monitoring Parameters. Use related parameters to evaluate college English teaching quality monitoring and intelligent analysis. College English teaching quality monitoring and intelligent analysis include parameters such as candidate numbers, class numbers, and adjustment coefficients. As shown in Figure 5, as the adjustment coefficient increases, the functions of the college English teaching quality monitoring and intelligent analysis system will become more complete. So as to acquire and master some of students' needs, analyze the results, and find out the most concerned problems of the students for a unified solution.

As shown in Table 7 , the sensitivity test of the game model, the supply chain operation reference model, and the IoT technology upgrade model show that the IoT technology upgrade model performs best. Adjustment coefficient $=-102 ; \mathrm{Di}=-99.6$; turnover $=-100$; system cost $=-123.2 ; \mathrm{SL}=-123.5 ; \mathrm{SP}=-99.8$. As shown in Figure 6, it is a visual representation of the results.
4.4. The Actual Measurement of the Optimization Model of the Internet of Things Technology in the English Classroom. For the actual testing of the upgraded and transformed model of the Internet of Things in the English classroom of the university, the model is judged by measuring the number of questions, the feedback rate, the number of students in the classroom, the test results of the class, the number of new words, the system score, and the comprehensive score. It is found that the number of questions, feedback rate, number of classmates, class test scores, number of new vocabulary, system scoring, and comprehensive scoring of the model after the upgrade and transformation of the Internet of Things are above the standard value, indicating that the model is highly efficient and intelligent. As shown in Table 8 and Figure 7.

\section{Conclusion}

With the continuous development of network communication, modern control, information perception, artificial intelligence, and other technologies, the Internet of Things technology has also been more comprehensively developed and grown, and it is playing an increasing role in various fields of production and life. Due to the low efficiency and cumbersome procedures of the existing college English teaching quality assessment, this study intends to propose a new method to deal with this problem. Through this research, we get the following: (1) use static weight equalization method, dynamic weight adaptation method, and iterative weight method to filter and analyze the original data received by mobile phones and discard some obviously wrong values in the preprocessing. Analyzing the number requirements of the game model, the supply chain operation reference model, and the IoT technology upgrade model for the number of demand points, the results show that the IoT technology upgrade model requires the least number of demand points. (2) Optimize the related parameter information of the IoT system model, including candidate numbers, number of students in class, adjustment coefficient, Di, turnover rate, system cost, and total system consumption. The Internet of Things technology upgrade model performed best. Adjustment coefficient $=-102 ; \mathrm{Di}=-99.6$; turnover $=$ $-100 ;$ system cost $=-123.2 ; \quad \mathrm{SL}=-123.5 ; \quad \mathrm{SP}=-99.8$. (3) Passed the test of the number of questions and feedback rate, classroom number, classroom test scores, new vocabulary number, system scoring, and comprehensive scoring to judge the model. It is found that the number of questions, feedback rate, class number, class test scores, number of new vocabularies, system scores, and comprehensive scores of the upgraded and transformed models of the Internet of Things are above the standard values, indicating that the model is highly efficient and intelligent.

\section{Data Availability}

The experimental data used to support the findings of this study are available from the corresponding author upon request. 


\section{Conflicts of Interest}

The author declared that there is no conflict of interest regarding this work.

\section{References}

[1] A. Osseiran, O. Elloumi, J. Song, and J. F. Monserrat, "Internet-of-Things (IoT)," IEEE Communications Standards Magazine, vol. 2, no. 2, pp. 70-76, 2018.

[2] S. Perumal, N. M. Norwawi, and V. Raman, "Internet of Things (IoT) digital forensic investigation model: top-down forensic approach methodology," in 2015 Fifth International Conference on Digital Information Processing and Communications (ICDIPC), pp. 19-23, Sierre, Switzerland, 2015.

[3] J. C. Han, H. W. Wang, X. L. Gao, and Y. Liu, "The discussion on application feasibility of "Internet of Things (IOT)" in the urban stormwater intelligent management," Journal of Fudan University(Natural Science), vol. 15, pp. 5-16, 2013.

[4] V. Borges, "Survey of context information fusion for ubiquitous Internet-of-Things (IoT) systems," Science, vol. 6, no. 1, pp. 64-78, 2016.

[5] O. Bello and S. Zeadally, "Toward efficient smartification of the Internet of Things (IoT) services," Future Generation Computer Systems, vol. 92, 2019.

[6] M. A. Li, H. Wang, L. Z. Yang, L. Z. Xia, and L. Y. Dong, "Construction and operation of soil temperature and moisture remote monitoring system based on Internet of Things(IOT)," The Soil, vol. 46, no. 3, pp. 526-533, 2014.

[7] R. Pillai and B. Sivathanu, "Adoption of Internet of Things (IoT) in the agriculture industry deploying the BRT framework," International Journal, vol. 27, no. 4, pp. 1341-1368, 2020.

[8] L. J. Albert, S. Rodan, N. Aggarwal, and T. R. Hill, "Gender and generational differences in consumers' perceptions of Internet of Things (IoT) devices," E-Journal of Social \& Behavioural Research in Business, vol. 10, 2019.

[9] P. Kaur, R. Kumar, and M. Kumar, "A healthcare monitoring system using random forest and internet of things (IoT)," Multimedia Tools \& Applications, vol. 78, no. 14, pp. 19905-19916, 2019.

[10] Y. Jin and G. Jin, "Foreign language teaching reform and improvement of college English teaching quality," Asian Social Science, vol. 4, no. 4, p. 127, 2009.

[11] X. Ning, K. Gong, W. Li, L. Zhang, X. Bai, and S. Tian, "Feature refinement and filter network for person re-identification," IEEE Transactions on Circuits and Systems for Video Technology, vol. 31, no. 9, pp. 3391-3402, 2021.

[12] J. J. Wang, "Research on the construction of higher vocational college English teaching quality evaluation system," Journal of Liaoning Higher Vocational, vol. 29, no. 10, pp. 12-26, 2018.

[13] R. Tang, "Focus on fossilization study, promote college English teaching quality in medical universities," Continuing Medical Education, vol. 78, no. 14, pp. 105-116, 2017.

[14] Y. Zheng, "Deepening reform of college English teaching in private institutions of higher learning and improving English teaching quality," Higher Education of Sanjiang University, vol. 110, pp. 02-15, 2016.

[15] X. Wang, "Teacher-student relationship and quality education in College and university english teaching," Higher Education of Social Science, vol. 3, no. 14, 2012.
[16] C. Wang, X. Wang, J. Zhang et al., "Uncertainty estimation for stereo matching based on evidential deep learning," Pattern Recognition, vol. 124, 2022.

[17] L. I. Gang, F. Lin, and Department P, "Study on application of Internet of Things(IOT) technology on railway freight collecting \& distributing center," Railway Freight Transport, vol. 2, pp. 18-23, 2014.

[18] R. P. Singh, M. Javaid, A. Haleem, and R. Suman, "Internet of things (IoT) applications to fight against COVID-19 pandemic," Diabetes and Metabolic Syndrome: Clinical Research and Reviews, vol. 14, no. 4, pp. 521-524, 2020.

[19] C. Beretas, "Internet of Things (IoT) is smart homes and the risks," Science, vol. 1, no. 5, 2019.

[20] F. Karatas and I. Korpeoglu, "Fog-based data distribution service (F-DAD) for Internet of Things (IoT) applications," Future Generation Computer Systems, vol. 93, pp. 156-169, 2019.

[21] D. G. Roy, B. Mahato, D. De, and R. Buyya, "Applicationaware end-to-end delay and message loss estimation in Internet of Things (IoT) - MQTT-SN protocols," Future Generation Computer Systems, vol. 89, pp. 300-316, 2018.

[22] G. Chen, L. Wang, M. Alam, and M. Elhoseny, "Intelligent group prediction algorithm of GPS trajectory based on vehicle communication," IEEE Transactions on Intelligent Transportation Systems, vol. 22, no. 7, pp. 3987-3996, 2021.

[23] A. Perles, E. Pérez-Marín, R. Mercado et al., "An energyefficient internet of things (IoT) architecture for preventive conservation of cultural heritage," Future Generation Computer Systems, vol. 81, pp. 566-581, 2018.

[24] M. Tu, “An exploratory study of Internet of Things (IoT) adoption intention in logistics and supply chain management," International Journal of Logistics Management, vol. 29, no. 1, pp. 131-151, 2018.

[25] Y. B. Zikria, H. Yu, M. K. Afzal, M. H. Rehmani, and O. Hahm, "Internet of Things (IoT): operating system, applications and protocols design, and validation techniques," Future Generation Computer Systems, vol. 88, pp. 699-706, 2018.

[26] G. B. Chen and S. Li, "Network on chip for enterprise information management and integration in intelligent physical systems," Enterprise Information Systems, vol. 15, no. 7, pp. 935-950, 2021.

[27] D. Satarupa, "Smart university utilising the concept of the Internet of Things (IoT)," Neurochemistry International, vol. 129, no. 10, 2019. 